\title{
Effects of soil organism interactions and temperature on carbon use efficiency in three different forest soils
}

\author{
Simin Wang ${ }^{1,2}$, Xiaoyun Chen ${ }^{3}$, Debao $\mathrm{Li}^{1,2}$, Jianping $\mathrm{Wu}^{1,2, *}$ \\ 1 Yunnan Key Laboratory of Plant Reproductive Adaptation and Evolutionary Ecology, Yunnan University, Kunming 650500, China \\ 2 School of Ecology and Environmental Sciences, Yunnan University, Kunming 650500, China \\ 3 Soil Ecology Lab, College of Resources and Environmental Sciences, Nanjing Agricultural University, Nanjing 210095, China
}

H I G H L I G H T S

- Three typical forest soils and three soil organisms were collected.

- Interactions among soils and organisms were examined by incubation experiment.

- Biotic factors mainly affect microbial CUE by changing biomass.

- Temperature regulates microbial CUE by affecting microbial respiration.

ARTICLE INFO

Article history:

Received June 9, 2020

Revised September 17, 2020

Accepted September 23, 2020

Keywords:

Biotic interactions

Carbon use efficiency

Climate gradients

Soil carbon cycle

Soil organisms

Soil respiration
GRAPHICAL ABSTRACT

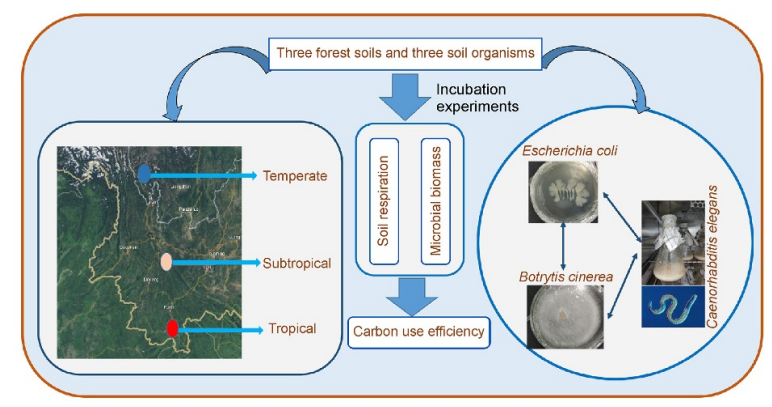

\begin{abstract}
A B S T R A C T
Microbial carbon use efficiency (CUE) affects the soil C cycle to a great extent, but how soil organisms and the abiotic environment combine to influence CUE at a regional scale remains poorly understood. In the current study, microcosms were used to investigate how microbial respiration, biomass, and CUE responded to biotic and abiotic factors in natural tropical, subtropical, and temperate forests. Soil samples from the forests were collected, sterilized, and populated with one or a combination of three types of soil organisms (the fungus Botrytis cinerea, the bacterium Escherichia coli, and the nematode Caenorhabditis elegans). The microcosms were then kept at the mean soil temperatures of the corresponding forests. Microbial respiration, biomass, and CUE were measured over one-month incubation period. The results showed that microbial biomass and CUE were significantly higher, but microbial respiration lower in the subtropical and temperate forest soils than in tropical forest soil. Biotic factors mainly affected CUE by their effect on microbial biomass, while temperature affected CUE by altering respiration. Our results indicate that temperature regulates the interactive effects of soil organisms on microbial biomass, respiration, and CUE, which would provide a basis for understanding the soil $\mathrm{C}$ cycle in forest ecosystems.
\end{abstract}

(c) Higher Education Press 2020

\section{Introduction}

Soil contains the largest carbon (C) pool in terrestrial ecosystems (Lal, 2004). Carbon emissions from the soil

\footnotetext{
* Corresponding author

E-mail address: jianping.wu@ynu.edu.cn (J. Wu)
}

make a significant contribution to the atmospheric $\mathrm{CO}_{2}$ concentration and therefore to global climate change (Melillo et al., 2017; Fang et al., 2018). The terrestrial C cycle is a vital biogeochemical cycle in which forest soils are especially important (Tang et al., 2018; Piao et al., 2020; SandersDeMott et al., 2020). Processes belowground are sensitive to environmental changes (Reinsch et al., 2017), and as such, soil $\mathrm{C}$ emissions are affected by the biotic and abiotic factors that contribute to these environmental changes ( $W u$ et al., 
2014; Eberwein et al., 2015; Estruch et al., 2020). The variance observed in soil respiration models, which are a function of soil $\mathrm{C}$ emissions, is mainly explained by abiotic factors such as temperature, moisture, and $C$ content of the soil (Kane et al., 2003; Rodeghiero and Cescatti, 2010; Li et al., 2020; Zhou et al., 2020). The influence of abiotic factors on soil $\mathrm{C}$ emissions has been extensively documented (Mancinelli et al., 2010; Butterly et al., 2019), however, the effect of biotic factors in different forest ecosystems has not been as well understood (Geisen et al., 2019).

Soil organisms regulate soil $\mathrm{C}$ storage and $\mathrm{CO}_{2}$ efflux via their decomposition activities (Moore et al., 2015; Zhu et al., 2016; Luo et al., 2020). $\mathrm{CO}_{2}$ efflux from the soil is altered by physiological and behavioral changes made by individual microbial populations (Hiscox et al., 2010; Crowther et al., 2011) and also by compositional changes in the microbial community (Crowther et al., 2015; Wu et al., 2019). Fungi, bacteria, and nematodes make substantial contributions to biogeochemical cycles as critical components of soil food webs (Bardgett and van der Putten, 2014; Crowther et al., 2019). Previous studies have concluded that $\mathrm{CO}_{2}$ efflux from the soil may be increased by the interactions between wooddecaying fungi (Maynard et al., 2017) and by nematodes feeding on microorganisms (Fu et al., 2005). Although the dynamics of $\mathrm{CO}_{2}$ efflux from the soil have been attributed to changes in soil organism diversity and/or community composition, little is known on the effects of soil organisms and their interactions on soil $\mathrm{CO}_{2}$ efflux.

Carbon use efficiency (CUE) has been used as a tool to gain an understanding of $\mathrm{C}$ storage and emission in ecosystems (Milcu et al., 2012; Wu et al., 2019); it is defined as the ratio of growth to total $\mathrm{C}$ uptake by organisms (Stefano et al., 2012; Tucker et al., 2012). Frequently used as a quantitative indicator reflecting $\mathrm{C}$ assimilation capacity and sequestration potential of soils, CUE is also important in the prediction of $\mathrm{C}$ feedback between soil organisms and the abiotic environment (Delucia et al., 2007; Davidson et al., 2014; McGee et al., 2019). A high CUE implies that soil organisms release less $C$ into the atmosphere, which is conducive for the stability and long-term retention of $C$ in the soil (Stefano et al., 2012; Dillaway and Kruger, 2014).

The effects of soil organisms, as the only factor, on CUE have been well documented (Sinsabaugh et al., 2013; Fang et al., 2020). However, the effects of their interactions with abiotic factors such as temperature, an important factor in soil respiration, on microbial CUE are yet to be established (Davidson et al., 2014; Maynard et al., 2017). In the current study, changes in microbial respiration, biomass, and CUE as a result of the interactions among the fungal, bacterial, and nematode populations in three forest soils (tropical, subtropical, and temperate) in Yunnan Province, China, were examined. The region was divided into the various ecosystem types according to geologic uplift, which is appropriate for the detection of interactions among soil organisms at a regional scale. We hypothesized that (1) interactions among soil organisms would affect microbial CUE due to changes in microbial biomass; and (2) microbial respiration would be different in the three forest soils due to their different mean annual temperatures, which would affect microbial CUE. To test these hypotheses, we conducted a laboratory incubation experiment with different combinations of forest soil types and soil organism populations.

\section{Materials and methods}

\subsection{Soil collection and pretreatment}

In July 2018, we collected surface soil $(0-10 \mathrm{~cm})$ in three forests in Yunnan Province, China. The forests were located in Xishuangbanna $\left(\mathrm{E} 101^{\circ} 25, \mathrm{~N} 21^{\circ} 41^{\prime}\right)$, Ailao Mountain $\left(\mathrm{E} 100^{\circ} 54^{\prime}-101^{\circ} 29^{\prime}, \mathrm{N}^{\circ} 4^{\circ} 00^{\prime}-24^{\circ} 44^{\prime}\right)$, and Shangrila $\left(\mathrm{E} 100^{\circ} 02^{\prime}, \mathrm{N} 27^{\circ} 13^{\prime}\right)$. Xishuangbanna has a tropical climate and a mean annual temperature of $21.5^{\circ} \mathrm{C}$. Ailao Mountain has a subtropical climate and a mean annual temperature of $11.6^{\circ} \mathrm{C}$ and Shangrila has a temperate climate and a mean annual temperature of $5.9^{\circ} \mathrm{C}$. At each site, ten $10 \times 10 \mathrm{~m}^{2}$ plots were established, in which nine $10 \times 10 \times 10 \mathrm{~cm}^{3}$ soil cores were collected. The soil samples from each location were mixed and analyzed for background organic $\mathrm{C}$ content, total nitrogen content, and $\mathrm{pH}$ which were found to be: $35.88 \mathrm{~g} \mathrm{~kg}^{-1}, 2.85 \mathrm{~g} \mathrm{~kg}^{-1}$, and 6.30 , respectively, for Xishuangbanna; $123.35 \mathrm{~g} \mathrm{~kg}^{-1}, 6.97 \mathrm{~g} \mathrm{~kg}^{-1}$ and 3.97 , respectively, for Ailao Mountain; and $93.54 \mathrm{~g} \mathrm{~kg}^{-1}$, $5.23 \mathrm{~g} \mathrm{~kg}^{-1}$ and 4.70, respectively, for Shangrila.

After plant debris and gravel were removed, each soil was mixed, passed through a $2-\mathrm{mm}$ sieve, and stored at $4^{\circ} \mathrm{C}$. A quantity of fresh soil (45.03 to $62.12 \mathrm{~g}$, equivalent to $30 \mathrm{~g}$ of dry soil) was transferred into a $500-\mathrm{mL}$ glass bottle with 24 bottles for each forest soil. After soil moisture was adjusted to $60 \%$ of maximum water holding capacity, the bottles were placed in a high-pressure steam sterilizer $\left(121^{\circ} \mathrm{C}\right)$ for $60 \mathrm{~min}$ to eliminate the original organisms in the soil. Respiration in the bottles was then measured to determine the presence of microorganisms that survived steam sterilization and was found to be very low, indicating that most but not all of the organisms had been removed. Respiration and biomass values for these "pretreatment" bottles were subtracted from all of the respiration and biomass values obtained following treatment in the study.

Each bottle was covered with a cap with a 2-mm-diameter hole in the center. A 2-mm-diameter PVC pipe was inserted a short distance into the hole, and the connection of the pipe to the hole was sealed with an adhesive. The PVC pipe was connected to a three-way valve outside the bottle. When the three-way valve was opened, gas could be exchanged in the bottle; when the valve was closed, a closed environment would be maintained inside the bottle.

\subsection{Experimental design and incubation conditions}

Three widely distributed soil organisms were selected for use in the experiment: the fungus Botrytis cinerea, the bacterium 
Escherichia coli, and the bacterivore nematode Caenorhabditis elegans. B. cinerea was obtained from the Soil Ecology Laboratory, Nanjing Agricultural University. E. coli and C. elegans were obtained from the State Key Laboratory for Conservation and Utilization of Bio-Resources in Yunnan. These organisms were added to the forest soils in the bottles in eight different combinations to create microcosms in a full factorial design: no organism, fungus alone, bacterium alone, nematode alone, fungus + bacterium, fungus + nematode, bacterium + nematode, and fungus + bacterium + nematode. The combination of all three organisms represented different communities in the incubation experiment, which reflects the interactions among organisms in the three forest soils. Each microcosm was replicated thrice, such that there were 24 bottles for each forest soil and 72 bottles in total. The $B$. cinerea and $E$. coli were added to the soil as previously described (Crowther et al., 2011; Maynard et al., 2017). In brief, $B$. cinerea was grown on potato dextrose agar medium, and $E$. coli was grown on lysogeny broth medium. $B$. cinerea and $E$. coli were added to the soil in the microcosms as 1.1$\mathrm{cm}$-diameter disks that had been removed from the solid media. Two disks of the indicated microorganism were added per microcosm for treatments with $B$. cinerea only and $E$. coli only, and one disk of each kind of indicated microorganism was added per microcosm for treatments that included two or three species. For treatments with $C$. elegans, 30 nematodes in a small volume of water (about $0.2 \mathrm{~mL}$ ) were added per microcosm. The number of nematodes added was based on a previous study in the region ( $\mathrm{Li}$ et al., 2009) and other incubation studies (Fu et al., 2005; Crowther et al., 2011).

After the organisms were added to the soils in the microcosms, the microcosms were covered with caps and the three-way valves were closed to maintain a closed environment. The microcosms were then placed in constant temperature incubators whose temperatures corresponded to the mean annual temperatures of the corresponding soils $\left(21.5^{\circ} \mathrm{C}\right.$ for tropical, $11.6^{\circ} \mathrm{C}$ for subtropical, and $5.9^{\circ} \mathrm{C}$ for temperate soils). Incubation lasted for a month as was the case in a similar trial (Maynard et al., 2017). After the commencement of incubation, the $\mathrm{CO}_{2}$ content of the atmosphere in each bottle was measured every two days with a gas chromatograph (GC9310, Shanghai, China). Gas was sampled with a 5-mL syringe that was connected to the threeway valve; the valve was opened to collect the sample and was then closed. The closed three-way valve was then connected to a new 5-mL syringe, the valve opened, and the new syringe was used to inject $5-\mathrm{mL}$ of free-air $\mathrm{CO}_{2}$ into the bottle to maintain the pressure balance. Also, the three-way valves were opened for an hour (this was done immediately after gas sampling) to allow gas exchange between the bottles and the exterior environment to prevent the $\mathrm{CO}_{2}$ content in the bottles from increasing to levels that would influence the activities of organisms. After one hour of gas exchange, another 5-mL sample of gas was collected from each bottle and assessed for $\mathrm{CO}_{2}$.

After incubation, the soil samples were assessed for biomass $\mathrm{C}$ content measured with a TOC analyzer (Elementar, Langenselbold, Germany) and the chloroform fumigation extraction method (Zhou et al., 2009).

\subsection{Microbial respiration and CUE determination}

The respiratory rates $\left(\mu \mathrm{g} \mathrm{CO} \mathrm{Cg}^{-1}\right.$ soil $\left.\mathrm{d}^{-1}\right)$ were determined as follows (Wu et al., 2014):

$$
R_{t}=\frac{M}{V_{0}} \cdot \frac{C_{t+2} V_{t+2}-C_{t} V_{t}}{2} \cdot \frac{1}{m} \cdot \frac{P}{P_{0}} \cdot \frac{T_{0}}{T_{a}}
$$

where $M=44 \mathrm{~g} \mathrm{~mol}^{-1} ; V_{O}=22.4 \mathrm{~L} \mathrm{~mol}^{-1} ; C=\mathrm{ppm}\left(1 \times 10^{-6}\right) ; V$ = gas volume $(\mathrm{mL})$ in the bottles; $m=30 \mathrm{~g} ; P=80.735 \mathrm{kPa}$ (atmospheric pressure in Kunming City, Yunnan Province, China); $P_{0}=101.325 \mathrm{kPa}$ (normal atmospheric pressure); $T_{0}=$ $273 \mathrm{~K}$; and $T_{\mathrm{a}}=$ temperature of incubation $(273+T) \mathrm{K}$. Because the respiration from soil fauna is usually small, all $\mathrm{CO}_{2}$ emissions in this study were attributed to soil microorganisms.

Respiration ( $\mu \mathrm{g} \mathrm{C} \mathrm{g}^{-1}$ soil) was determined as follows (Wu et al., 2014):

$$
R=\sum_{i=1}^{n}\left(R_{i} \cdot t\right) \cdot \frac{12}{44}
$$

CUE was determined as follows: (Maynard et al., 2017; Fang et al., 2020):

$$
\mathrm{CUE}=\frac{B}{B+R}
$$

where $B=$ content of biomass $\mathrm{C}$ ( $\mu \mathrm{g} \mathrm{C} \mathrm{g} \mathrm{g}^{-1}$ soil); and $R=$ content of respiration $C$ ( $\mu \mathrm{g} \mathrm{C} \mathrm{g}{ }^{-1}$ soil). The value of CUE ranges from 0 to 1 ; with a higher value indicating a higher CUE.

Predicted respiration, biomass, and CUE in incubated soil organism communities were determined as follows (Maynard et al., 2017):

$$
\begin{aligned}
& R_{p}=R_{\mathrm{b}}+R_{\mathrm{f}}+R_{\mathrm{n}} \\
& B_{p}=B_{\mathrm{b}}+B_{\mathrm{f}}+B_{\mathrm{n}} \\
& \mathrm{CUE}_{p}=\frac{B_{p}}{B_{p}+R_{p}}
\end{aligned}
$$

where $R_{\mathrm{b}} / B_{\mathrm{b}}, R_{\mathrm{f}} / B_{\mathrm{f}}$, and $R_{\mathrm{n}} / B_{\mathrm{n}}=$ respiration/biomass of bacteria, fungi, and nematodes, when incubated individually.

Proportional change in respiration, biomass, and CUE were determined as follows:

$$
\begin{gathered}
R^{\prime}=\frac{R-R_{P}}{R_{p}} \\
B^{\prime}=\frac{B-B_{P}}{B_{p}} \\
\mathrm{CUE}^{\prime}=\frac{C U E-C U E_{P}}{C U E_{p}}
\end{gathered}
$$

Proportional changes $>0$ indicate that the interactions among 
soil organisms increased soil respiration, biomass, or CUE. Proportional changes $<0$ indicate that interactions among soil organisms decreased soil respiration, biomass, or CUE. Proportional changes $=0$ indicate that interactions among soil organisms did not affect soil respiration, biomass, or CUE (Maynard et al., 2017).

\subsection{Statistical analysis}

One-way analyses of variance (ANOVA) were used to assess the effects of different combinations of organisms on respiration, biomass, and CUE in each forest soil (tropical, subtropical, and temperate). In the figures, mean values with different letters are significantly different at $P<0.05$. Three-way ANOVAs were used to assess the effects of $B$. cinerea, E. coli, C. elegans, and their interactions on respiration, biomass, and CUE in the forest soils. Regression analysis was used to analyze the relationships between population richness (number of species added) and respiration, biomass, and CUE. Pearson correlation analysis was used to determine relationships among respiration, biomass, and CUE vs. temperature against soil physicochemical properties. SPSS 16.0 (SPSS, Inc., Chicago, USA) was used for statistical analysis. The random forest modeling (package randomForest in $\mathrm{R}$ ) was used to quantitatively assess the effects of abiotic (temperature and respiration) and biotic (microbial biomass) variables on CUE.

\section{Results}

3.1 Microbial respiration, biomass, and CUE in different forest soils

Microbial respiration in the tropical forest soils did not show any significant differences among treatments (Fig. 1A). In the subtropical forest soil, microbial respiration in the fungus treatment was higher than in the bacterium, nematode, and bacterium + nematode treatments (Fig. 1B). In the temperate forest soil, microbial respiration in fungus + bacterium treatment was higher than nematode, bacterium + nematode, and fungus + nematode treatments (Fig. 1C). There also appeared to be no respiration occurring in temperate forest soil incubated with the nematodes. Among the treatments, microbial biomass was lowest with the fungus + bacterium + nematode treatment in all three forest soils (Fig. 1D-F). In subtropical and temperate forest soils, microbial CUE was significantly lower in the fungus + bacterium + nematode treatment than in the other treatments $(F i g .1 \mathrm{H}, \mathrm{I})$.

The mean microbial respiration for all treatments within a soil was significantly higher in the tropical forest soil than in the subtropical and temperate forest soils (Fig. 2A). The mean microbial biomass and CUE in the tropical soil were significantly lower than in the subtropical and temperate soils (Fig. 2B, C). The random forest modeling showed that $42.97 \%$ of the variation observed in CUE was a result of microbial respiration and temperature while $36.95 \%$ was attributed to microbial biomass (Fig. 2D). Microbial biomass was not correlated with any of the abiotic factors (Table 1). Microbial respiration was correlated with temperature and $\mathrm{C} / \mathrm{N}$ ( $P=0.007$ and 0.045 , respectively) while CUE was correlated only with temperature $(P<0.001)$. (Table 1$)$.

3.2 Microbial respiration, biomass, and CUE in different population combinations

In soil treatments with one and two species, microbial respiration was significantly higher in the tropical forest soil than in the temperate forest soil (Fig. 3A, B). Microbial respiration did not significantly differ in the 3 -species treatment (Fig. 3C). Microbial biomass was significantly higher with the 1-species treatment in subtropical soils compared to tropical and temperate soils. (Fig. 3D). In the 2-species treatment, microbial biomass was lowest in the tropical forest soil than in the other two soils (Fig. 3E). The CUE was significantly lower in the tropical forest soil containing one and two species than in the other two soils (Fig. 3G, H). No significant differences were observed in the 3-species treatments among the soils across all variables. There were no significant increases or decreases in microbial respiration with increases in the number of species in all soil types. Microbial biomass declined significantly with an increase in species number in the tropical and subtropical forest soils (Fig. 4D, E) but not in the temperate forest soil (Fig. 4F). CUE declined as species number increased in the subtropical and temperate forest soils (Fig. $4 \mathrm{H}, \mathrm{I})$.

The three-way ANOVA revealed that the fungus + bacterium and bacterium + nematode treatments significantly affected microbial biomass, while fungus + nematode, bacterium + nematode, and fungus + bacterium + nematode treatments significantly affected CUE in the three forest soils (Table 2). The interactive effects of the bacterium + nematode treatment tended to decrease microbial biomass, while the fungus + bacterium treatment increased microbial biomass and respiration (Fig. 5). All four of the interactive effects increased the CUE in the tropical forest soil and decreased or negligibly affected the CUE in the subtropical and temperate forest soils (Fig. 5).

\section{Discussion}

\subsection{Biotic factors affected CUE by changing biomass}

Previous studies have examined the effects of microorganisms on soil respiration, but few have delineated the relationships among respiration, biomass, and CUE (Graaff et al., 2015; Fang et al., 2020). The current study revealed that with an increase in the population diversity of soil organisms, microbial biomass and CUE declined, which suggests that the increase in population diversity may reduce CUE by reducing biomass. The changes in microbial biomass can be attributed to the interactions among soil organisms as evidenced by the effects of the bacterium + nematode treatment which 

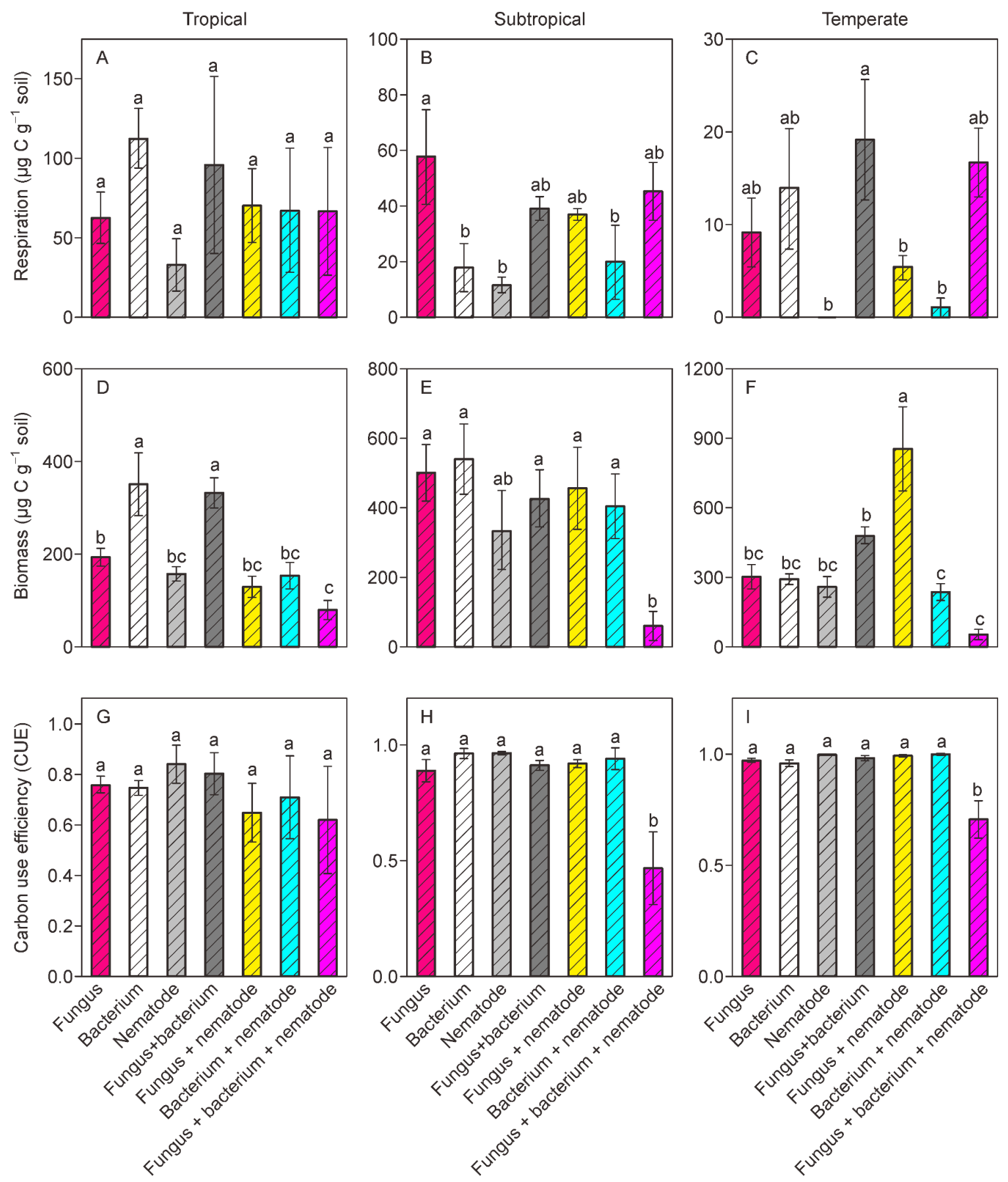

Fig. 1 Microbial respiration (A-C), biomass (D-F), and carbon use efficiency (CUE) (G-I) for all organism-addition treatments in the tropical, subtropical, and temperate forest soils. The seven organism-addition treatments are indicated on the $x$-axis. Values are means \pm SE $(n=3)$. In each panel, means with different letters are significantly different at $P<0.05$. 

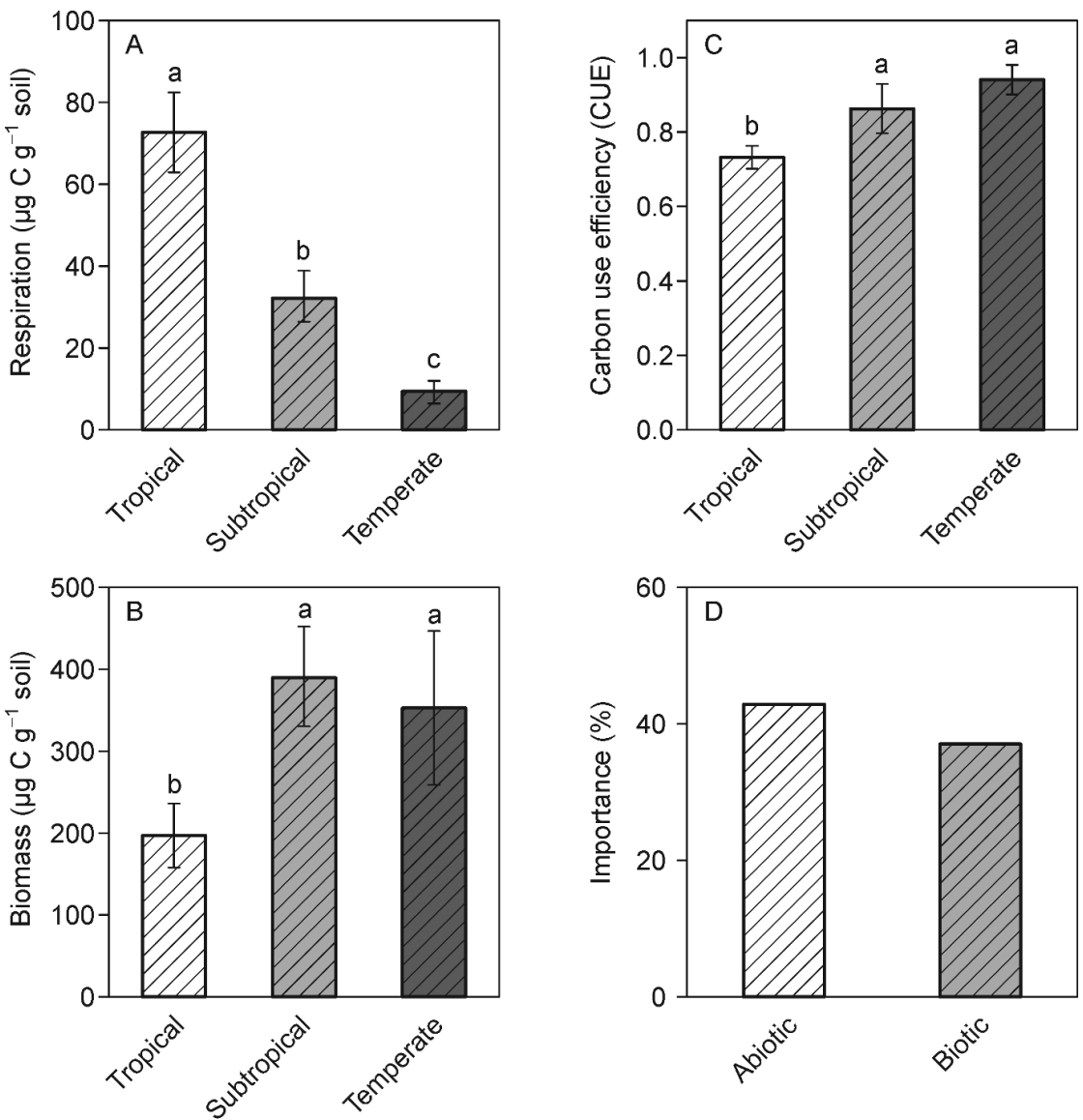

Fig. 2 Microbial respiration (A), biomass (B), carbon use efficiency (C), and importance of abiotic and biotic factors (D) averaged across all organism-addition treatments in the tropical, subtropical, and temperate forest soils. Values are means $\pm S E(n=21)$. In each panel, means with different letters are significantly different at $P<0.05$.

decreased microbial biomass in all three forest soils. This is in agreement with other work that has shown a negative correlation between microbial biomass and species richness (Nielsen et al., 2011; Li et al., 2020). On the other hand, it has been reported that soil biota composition rather than species richness regulated soil $C$ sequestration and emission, indicating that community composition and population diversity may have different effects on the soil carbon cycle (De Deyn, 2013). This suggests that the effects of population diversity on microbial respiration could be a consequence of functional compositional changes in the soil community.
We also found that biotic factors rarely affected microbial respiration, i.e., microbial respiration was influenced by biotic factors in only three of the twenty-one treatment combinations; this may indicate that the biotic factors affected CUE by changing biomass. We speculate that the effects of species diversity on microbial respiration were marginal in our incubation experiment since microbial respiration in the three forest soils did not follow any particular trend with changes in species diversity. Maynard et al., (2017) reported that biotic factors contributed more to the variation in CUE than abiotic factors and that interactions among microorgan-

Table 1 Correlation coefficients $(r$ values) and $P$ values $(n=3)$ for relationships among soil respiration, biomass, and CUE vs. soil physicochemical properties.

\begin{tabular}{|c|c|c|c|c|c|c|c|c|c|c|c|c|c|c|}
\hline \multirow[t]{2}{*}{ Factors } & \multicolumn{2}{|c|}{ Temperature } & \multicolumn{2}{|c|}{ SOC } & \multicolumn{2}{|c|}{ DOC } & \multicolumn{2}{|c|}{$\mathrm{TN}$} & \multicolumn{2}{|c|}{ TP } & \multicolumn{2}{|c|}{ AP } & \multicolumn{2}{|c|}{$\mathrm{C} / \mathrm{N}$} \\
\hline & $r$ & $P$ & $r$ & $P$ & $r$ & $P$ & $r$ & $P$ & $r$ & $P$ & $r$ & $P$ & $r$ & $P$ \\
\hline Respiration & 1.000 & 0.007 & -0.758 & 0.452 & -0.988 & 0.098 & -0.695 & 0.511 & -0.993 & 0.077 & 0.843 & 0.361 & 0.997 & 0.045 \\
\hline Biomass & -0.843 & 0.361 & 0.988 & 0.098 & 0.921 & 0.255 & 0.970 & 0.157 & 0.907 & 0.277 & -0.432 & 0.715 & 0.885 & 0.309 \\
\hline CUE & -1.000 & $<0.001$ & 0.751 & 0.459 & 0.986 & 0.106 & 0.687 & 0.518 & 0.991 & 0.085 & -0.849 & 0.354 & 0.997 & 0.053 \\
\hline
\end{tabular}

Notes: $\mathrm{SOC}=$ soil organic carbon; $\mathrm{DOC}=$ dissolved organic carbon; $\mathrm{TN}=$ total nitrogen; $\mathrm{TP}=$ total phosphorus; $\mathrm{AP}=$ available phosphorus; $\mathrm{C} / \mathrm{N}=$ SOC/TN. 

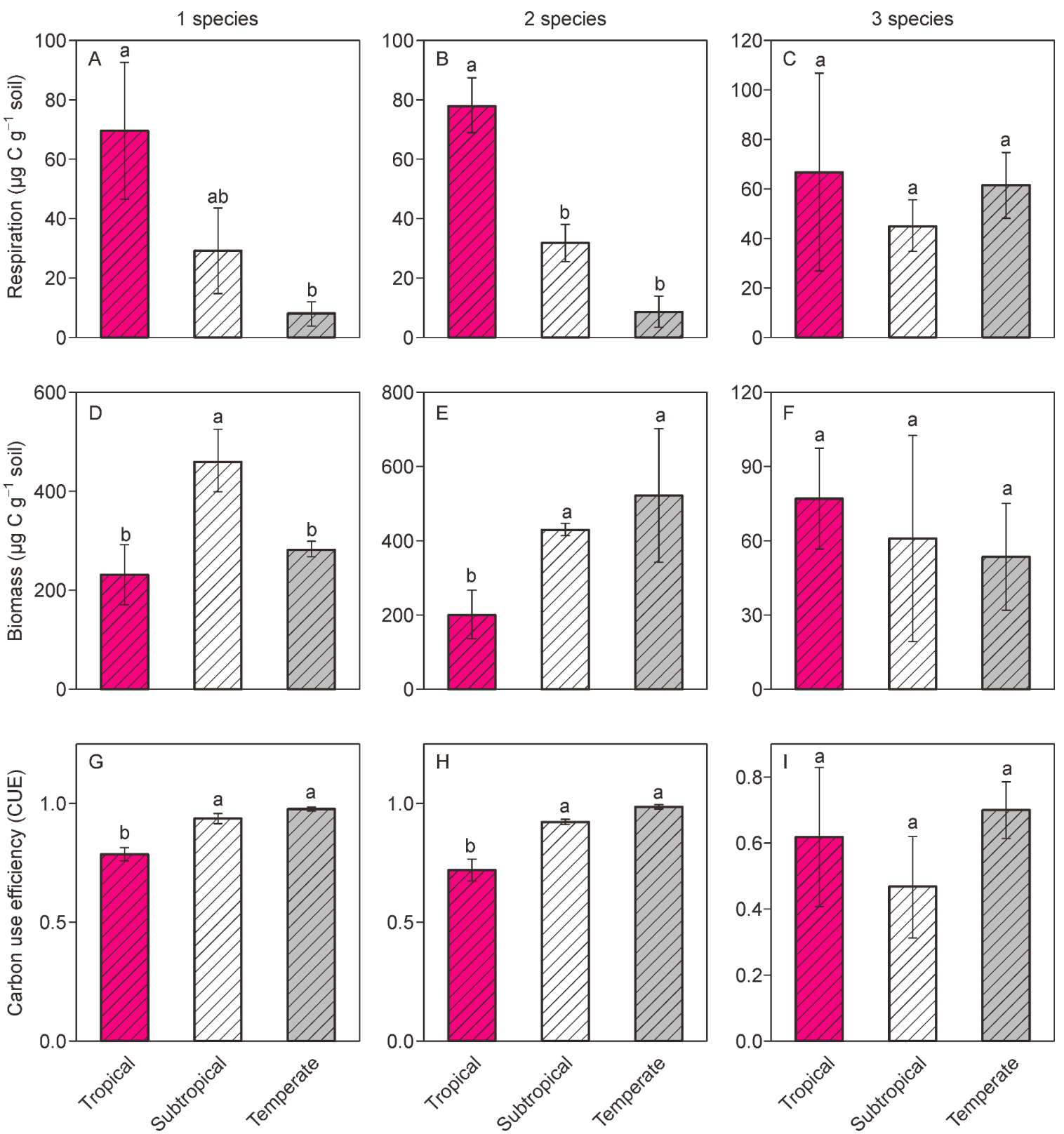

Fig. 3 Microbial respiration $(A-C)$, biomass $(D-F)$, and carbon use efficiency $(G-I)$ as affected by the number of species added to the tropical, subtropical, and temperate forest soils. Values are means \pm SE. $n=3$ when one or three species were added and $=9$ when two species were added. In each panel, means with different letters are significantly different at $P<0.05$.

isms reduced CUE, which is similar to what was observed in the current study. This could have been caused by differences in functional composition where the $C$. elegans, a bacterivore, altered the microbial biomass due to its feeding behavior and consequently affected CUE (Fu et al., 2005). The current work points to biotic influence on CUE mediated by changes in biomass rather than respiration in the forest soils studied.

\subsection{Abiotic factors affected CUE by changing respiration}

Microbial respiration and CUE but not microbial biomass were significantly correlated to temperature in the three forest soils as shown in the correlation analysis. Microbial CUE declined as temperature increased in the current study probably because an increase in temperature led to an increase in respiration and a subsequent decrease in CUE (Stefano et al., 2012; Tucker et al., 2012). In a study involving multiple sites in the Italian Alps, Rodeghiero and Cescatti (2010) fitted soil respiration, temperature, and other environmental variables into a simple logistic model and found that mean soil annual temperature explained most of the intersite variation in soil respiration, this is consistent with our finding that temperature and microbial respiration accounted for over $40 \%$ of the variation seen in CUE. 

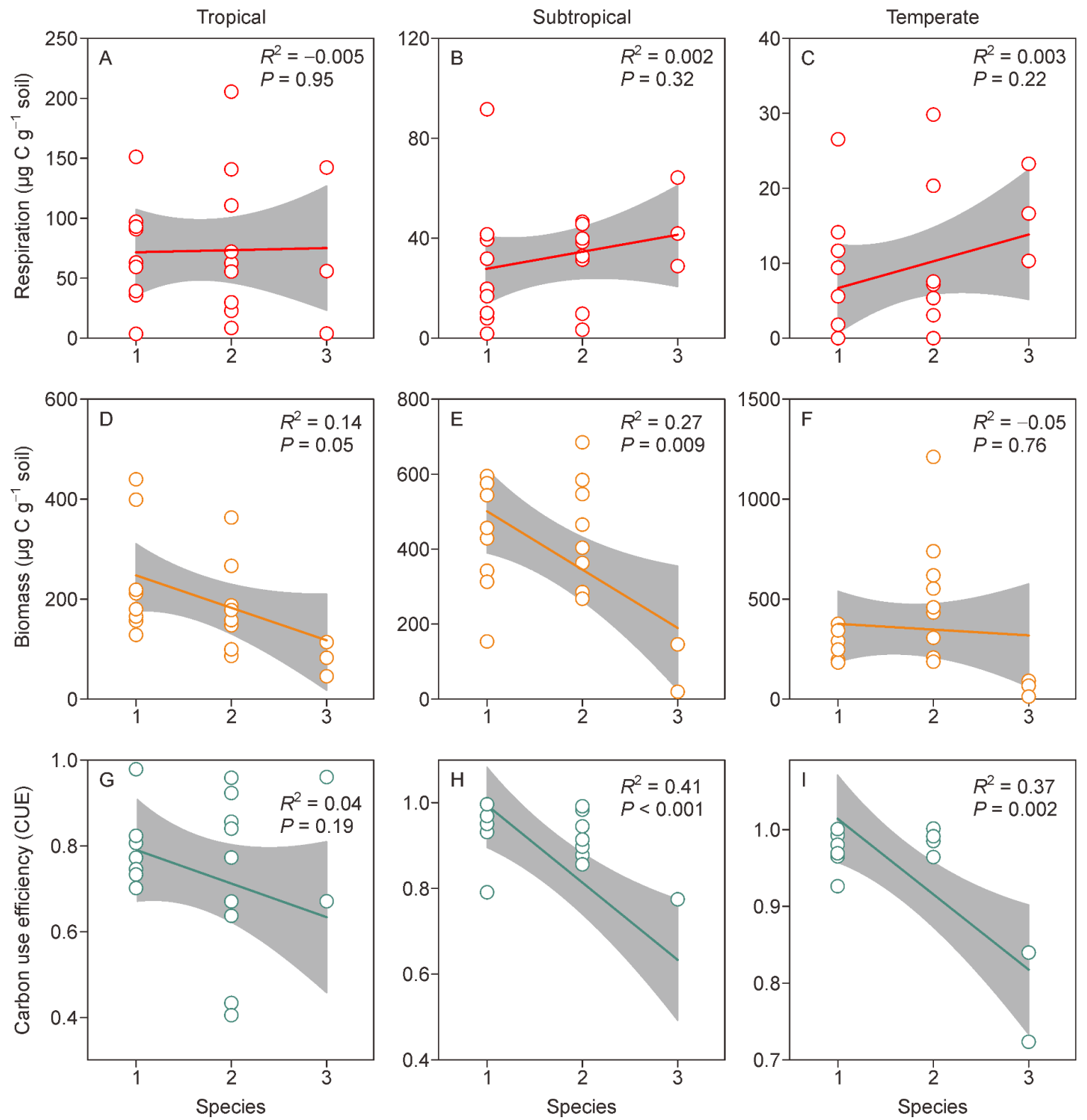

Fig. 4 Relationships between the number of species added and microbial respiration (A-C), biomass (D-F), and carbon use efficiency (G-I) in the tropical, subtropical, and temperate forest soils. $n=3$ when one or three species were added and $=9$ when two species were added. Linear regression statistics are indicated.

As indicated in a recent review (Wu et al., 2019) as well as earlier studies (Chambers et al., 2004; Delucia et al., 2007), plant and microbial CUEs are lower in tropical ecosystems compared to temperate ones. These CUE variations among different ecosystems can be at least partially explained by temperature (Geyer et al., 2016). In other work, for example, temperature was considered the main factor affecting respiration and decomposition rates in soil (Giardina and Ryan, 2000; Davidson and Janssens, 2006; Jing et al., 2015), which is in line with our findings. We would also like to point out that $\mathrm{C} / \mathrm{N}$ affected microbial respiration in this study. Since soil nutrient traits can affect CUE due to different substrates for microorganisms in different soils. Additional studies with other forest types and for longer incubation durations are necessary to verify this inference.

\section{Conclusions}

Our assessment of the effects of abiotic and biotic factors on soil respiration, microbial biomass, and microbial CUE indicates that these factors affected CUE differently at a regional scale. Temperature mainly affected CUE by changing 


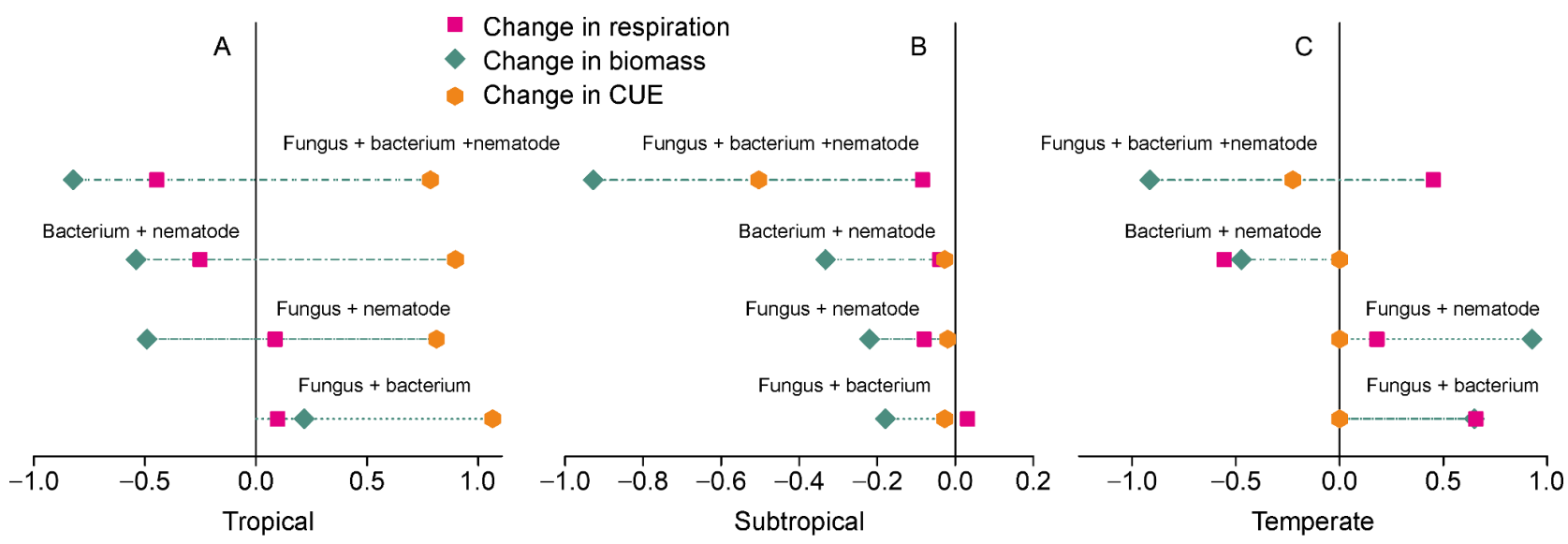

Fig. 5 The proportional changes in microbial respiration (pink symbols), biomass (green symbols), and carbon use efficiency (orange symbols) in the tropical (A), subtropical (B), and temperate (C) forest soils. $n=3$ when one or three species were added and $=9$ when two species were added.

Table 2 The effects of fungus (Botrytis cinerea), bacterium (Escherichia coli), nematode (Caenorhabditis elegans) and their interactions on microbial respiration, biomass, and carbon use efficiency (CUE) as indicated by a three-way analysis of variances $(n=3)$.

\begin{tabular}{|c|c|c|c|c|c|c|c|c|c|c|c|c|c|c|c|}
\hline \multirow[t]{2}{*}{ Factors } & \multirow[t]{2}{*}{ Forest soil } & \multicolumn{2}{|c|}{ Fungus } & \multicolumn{2}{|c|}{ Bacterium } & \multicolumn{2}{|c|}{ Nematode } & \multicolumn{2}{|c|}{$\begin{array}{l}\text { Fungus } \times \\
\text { Bacterium }\end{array}$} & \multicolumn{2}{|c|}{$\begin{array}{l}\text { Fungus } \times \\
\text { Nematode }\end{array}$} & \multicolumn{2}{|c|}{$\begin{array}{c}\text { Bacterium } \times \\
\text { Nematode }\end{array}$} & \multicolumn{2}{|c|}{$\begin{array}{c}\text { Fungus } \times \\
\text { Bacterium } \times \\
\text { Nematode }\end{array}$} \\
\hline & & $F$ & $P$ & $F$ & $P$ & $F$ & $P$ & $F$ & $P$ & $F$ & $P$ & $F$ & $P$ & $F$ & $P$ \\
\hline \multirow[t]{3}{*}{ Respiration } & Tropical & 0.89 & 0.359 & 4.11 & 0.060 & 0.15 & 0.703 & 1.80 & 0.199 & 0.01 & 0.910 & 1.77 & 0.202 & 0.23 & 0.640 \\
\hline & Subtropical & 24.89 & $<0.001$ & 0.35 & 0.561 & 0.00 & 0.961 & 1.96 & 0.180 & 1.15 & 0.300 & 0.43 & 0.520 & 1.98 & 0.178 \\
\hline & Temperate & 10.85 & 0.005 & 11.30 & 0.004 & 3.11 & 0.097 & 0.34 & 0.568 & 0.39 & 0.543 & 1.13 & 0.303 & 1.75 & 0.205 \\
\hline \multirow[t]{3}{*}{ Biomass } & Tropical & 0.62 & 0.442 & 23.46 & $<0.001$ & 16.08 & 0.001 & 8.23 & 0.011 & 9.24 & 0.008 & 36.59 & $<0.001$ & 3.37 & 0.085 \\
\hline & Subtropical & 0.45 & 0.511 & 0.32 & 0.579 & 0.75 & 0.398 & 19.16 & $<0.001$ & 6.10 & 0.025 & 10.33 & 0.005 & 0.38 & 0.545 \\
\hline & Temperate & 20.02 & $<0.001$ & 3.03 & 0.101 & 2.48 & 0.135 & 19.17 & $<0.001$ & 0.12 & 0.737 & 40.47 & $<0.001$ & 10.61 & 0.005 \\
\hline \multirow[t]{3}{*}{ CUE } & Tropical & 2.80 & 0.114 & 3.95 & 0.064 & 2.59 & 0.127 & 3.54 & 0.078 & 12.11 & 0.003 & 8.98 & 0.009 & 6.53 & 0.021 \\
\hline & Subtropical & 3.43 & 0.083 & 8.82 & 0.009 & 9.28 & 0.008 & 62.49 & $<0.001$ & 61.28 & $<0.001$ & 71.97 & $<0.001$ & 8.59 & 0.010 \\
\hline & Temperate & 63.72 & $<0.001$ & 60.09 & $<0.001$ & 80.64 & $<0.001$ & 203.81 & $<0.001$ & 221.7 & $<0.001$ & 210.4 & $<0.001$ & 58.91 & $<0.001$ \\
\hline
\end{tabular}

respiration, while biotic factors affected CUE mainly by changing microbial biomass in the different forest soils. The modifying effects of biotic and abiotic factors on the soil carbon cycle appear to be dependent on forest ecosystem type. This provides new insights that could be expanded in future studies of belowground biodiversity and ecosystem function.

\section{Acknowledgments}

We are grateful to Zhiyun Lu and Hui Chen from XTBG, CAS for their assistance in field sampling. This work was financially supported by the National Natural Science Foundation of China (No. 31971497) and by "Young Scholar" funding from Yunnan Province.

\section{Author contributions}

JPW and SMW conceived and designed the experiments. All authors analyzed the data and jointly wrote the manuscript.

\section{Competing financial interests}

The authors declare no competing financial interests.

\section{References}

Bardgett, R.D., van der Putten, W.H., 2014. Belowground biodiversity and ecosystem functioning. Nature 515, 505-511.

Butterly, C.R., Armstrong, R.D., Chen, D., Tang, C., 2019. Residue 
decomposition and soil carbon priming in three contrasting soils previously exposed to elevated $\mathrm{CO}_{2}$. Biology and Fertility of Soils $55,17-29$.

Chambers, J.Q., Tribuzy, E.S., Toledo, L.C., Crispim, B.F., Higuchi, N., Santos, J.D., Araujo, A.C., Kruijt, B., Nobre, A.D., Trumbore, S. E., 2004. Respiration from a tropical forest ecosystem: partitioning of sources and low carbon use efficiency. Ecological Applications $14,72-88$.

Crowther, T.W., Hoogen, J.V.D., Wan, J., Mayes, M.A., Keiser, A.D., Mo, L., 2019. The global soil community and its influence on biogeochemistry. Science 365, 1-10.

Crowther, T.W., Jones, T.H., Boddy, L., Baldrian, P., 2011. Invertebrate grazing determines enzyme production by basidiomycete fungi. Soil Biology \& Biochemistry 43, 2060-2068.

Crowther, T.W., Thomas, S.M., Maynard, D.S., Baldrian, P., Covey, K., Frey, S.D., van Diepen, L.T.A., van Bradford, M.A., 2015. Biotic interactions mediate soil microbial feedbacks to climate change. Proceedings of the National Academy of Sciences of the United States of America 112, 7033-7038.

Davidson, E.A., Janssens, I.A., 2006. Temperature sensitivity of soil carbon decomposition and feedbacks to climate change. Nature 440, 165-173.

Davidson, E.A., Savage, K.E., Finzi, A.C., 2014. A big-microsite framework for soil carbon modeling. Global Change Biology 20, 3610-3620.

De Deyn, G.B., 2013. Ecosystem Carbon and Soil Biodiversity. In Lal, R., Lorenz, K., Hüttl, R.F., Schneider, B.U., von Braun, J., eds. Ecosystem Services and Carbon Sequestration in the Biosphere. Springer, Netherlands, 131-153.

Delucia, E.H., Drake, J.E., Thomas, R.B., Gonzalez-Meler, M., 2007. Forest carbon use efficiency: is respiration a constant fraction of gross primary production? Global Change Biology 13, 11571167.

Dillaway, D.N., Kruger, E.L., 2014. Trends in seedling growth and carbon-use efficiency vary among broadleaf tree species along a latitudinal transect in eastern North America. Global Change Biology 20, 908-922.

Eberwein, J.R., Oikawa, P.Y., Allsman, L.A., Jenerette, G.D., 2015. Carbon availability regulates soil respiration response to nitrogen and temperature. Soil Biology \& Biochemistry 88, 158-164.

Estruch, C., Macek, P., Armas, C., Pistón, N., Pugnaire, F.I., 2020. Species identity improves soil respiration predictions in a semiarid scrubland. Geoderma 363, 114153.

Fang, J., Yu, G., Liu, L., Hu, S., Chapin, F.S. III, 2018. Climate change, human impacts, and carbon sequestration in China. Proceedings of the National Academy of Sciences of the United States of America 115, 4015-4020.

Fang, Y., Singh, B.P., Collins, D., Armstrong, R., van Zwieten, L., Tavakkoli, E., 2020. Nutrient stoichiometry and labile carbon content of organic amendments control microbial biomass and carbon-use efficiency in a poorly structured sodic-subsoil. Biology and Fertility of Soils 56, 219-223.

Fu, S., Ferris, H., Brown, D., Plant, R., 2005. Does the positive feedback effect of nematodes on the biomass and activity of their bacteria prey vary with nematode species and population size? Soil Biology \& Biochemistry 37, 1979-1987.
Geisen, S., Briones, M., Gan, H., Behan-Pelletier, V., Friman, V.P., Groot, G., Hannula, S., Lindo, Z., Philippot, L., Tivnov, A., Wall, D., 2019. A methodological framework to embrace soil biodiversity. Soil Biology \& Biochemistry 136, 107536.

Geyer, K.M., Kyker-Snowman, E., Grandy, A.S., Frey, S.D., 2016. Microbial carbon use efficiency: accounting for population, community, and ecosystem-scale controls over the fate of metabolized organic matter. Biogeochemistry 127, 173-188.

Giardina, C.P., Ryan, M.G., 2000. Evidence that decomposition rates of organic carbon in mineral soil donot vary with temperature. Nature 404, 858-861.

Graaff, M.A.D., Adkins, J., Kardol, P., Throop, H.L., 2015. A metaanalysis of soil biodiversity impacts on the carbon cycle. Soil (Göttingen) 1, 907-945.

Hiscox, J., Baldrian, P., Rogers, H.J., Boddy, L., 2010. Changes in oxidative enzyme activity during interspecific mycelial interactions involving the white-rot fungus Trametes versicolor. Fungal Genetics and Biology 47, 562-571.

Jing, W., Chen, S., Zheng, H., Zhang, X., 2015. Soil microbial respiration under different soil temperature conditions and its relationship to soil dissolved organic carbon and invertase. Environmental Sciences (Ruse) 36, 1497-1506.

Kane, E.S., Pregitzer, K.S., Burton, A.J., 2003. Soil respiration along environmental gradients in Olympic National Park. Ecosystems (New York, N.Y.) 6, 326-335.

Lal, R., 2004. Soil carbon sequestration impacts on global climate change and food security. Science 304, 1623-1627.

Li, J., Pei, J., Pendall, E., Fang, C., Nie, M., 2020. Spatial heterogeneity of temperature sensitivity of soil respiration: $A$ global analysis of field observations. Soil Biology \& Biochemistry 141, 107675.

Li, Y., Yang, X., Zou, X., Wu, J., 2009. Response of soil nematode communities to tree girdling in a subtropical evergreen broadleaved forest of southwest China. Soil Biology \& Biochemistry 41, 877-882.

Luo, R., Kuzyakov, Y., Liu, D., Fan, J., Luo, J., Stuart, L., He, J., Ding, W., 2020. Nutrient addition reduces carbon sequestration in a Tibetan grassland soil: Disentangling microbial and physical controls. Soil Biology \& Biochemistry 144, 107764.

Mancinelli, R., Campiglia, E., Tizio, A.D., Marinari, S., 2010. Soil carbon dioxide emission and carbon content as affected by conventional and organic cropping systems in Mediterranean environment. Applied Soil Ecology 46, 64-72.

Maynard, D.S., Crowther, T.W., Bradford, M.A., 2017. Fungal interactions reduce carbon use efficiency. Ecology Letters 20, 1034-1042.

McGee, K.M., Eaton, W.D., Shokralla, S., Hajibabaei, M., 2019. Determinants of soil bacterial and fungal community composition toward carbon-use efficiency across primary and secondary forests in a Costa Rican conservation area. Microbial Ecology 77, 148-167.

Melillo, J.M., Frey, S.D., De Angelis, K.M., Werner, W.J., Bernard, M. J., Bowles, F.P., Pold, D., Knorr, M.A., Grandy, A.S., 2017. Longterm pattern and magnitude of soil carbon feedback to the climate system in a warming world. Science 358, 101-105.

Milcu, A., Lukac, M., Subke, J.A., Manning, P., Heinemeyer, A., 
Wildman, D., Anderson, R., Ineson, P., 2012. Biotic carbon feedbacks in a materially closed soil-vegetation-atmosphere system. Nature Climate Change 2, 291-294.

Moore, J.A.M., Jiang, J., Post, W.M., Classen, A.T., 2015. Decomposition by ectomycorrhizal fungi alters soil carbon storage in a simulation model. Ecosphere 6, 1-16.

Nielsen, U.N., Ayres, E., Wall, D.H., Bardgett, R.D., 2011. Soil biodiversity and carbon cycling: A review and synthesis of studies examining diversity-function relationships. European Journal of Soil Science 62, 105-116.

Piao, S., Wang, X., Wang, K., Li, X., Ana, B., Josep, G.C., Philippe, C., Pierre, F., Stephen, S., 2020. Interannual variation of terrestrial carbon cycle: Issues and perspectives. Global Change Biology 26, 300-318.

Reinsch, S., Koller, E., Sowerby, A., de Dato, D.G., Estiarte, M., Guidolotti, G., Kovács-Láng, E., Kröel-Dulay, G., Lellei-Kovács, E., Larsen, K.S., Liberati, D., Peñuelas, J., Ransijn, J., Robinson, D.A., Schmidt, I.K., Smith, A.R., Tietema, A., Dukes, J.S., Beier, C., Emmett, B.A., 2017. Shrubland primary production and soil respiration diverge along European climate gradient. Scientific Reports 7, 1-7.

Rodeghiero, M., Cescatti, A., 2010. Main determinants of forest soil respiration along an elevation/temperature gradient in the Italian Alps. Global Change Biology 11, 1024-1041.

Sanders-DeMott, R., Ouimette, A.P., Lepine, L.C., Fogarty, S.Z., Burakowski, E.A., Contosta, A.R., Ollinger, S.V., 2020. Divergent carbon cycle response of forest and grass-dominated northern temperate ecosystems to record winter warming. Global Change Biology 26, 1519-1531.

Sinsabaugh, R.L., Stefano, M., Moorhead, D.L., Andreas, R., 2013. Carbon use efficiency of microbial communities: stoichiometry, methodology and modelling. Ecology Letters 16, 930-939.

Stefano, M., Philip, T., Andreas, R., Amilcare, P., Agren, G.I., 2012. Environmental and stoichiometric controls on microbial carbon- use efficiency in soils. New Phytologist 196, 79-91.

Tang, X., Zhao, X., Bai, Y., Tang, Z., Wang, W., Zhao, Y., Wan,H., Xie, Z., Shi, X., Wu, B., Wang, G., Yan, J., Ma, K., Du, S., Li, S., Han, S., Ma, Y., Hu, H., He, N., Yang, Y., Han, W., He, H., Yu, G., Fang, G., Zhou, G., 2018. Carbon pools in China's terrestrial ecosystems: New estimates based on an intensive field survey. Proceedings of the National Academy of Sciences of the United States of America 15, 4021-4026.

Tucker, C.L., Bell, J., Pendall, E., Ogle, K., 2012. Does declining carbon-use efficiency explain thermal acclimation of soil respiration with warming? Global Change Biology 19, 252-263.

Wu, C., Zhang, Y., Xu, X., Sha, L., You, G., Liu, Y., Xie, Y., 2014. Influence of interactions between litter decomposition and rhizosphere activity on soil respiration and on the temperature sensitivity in a subtropical montane forest in SW China. Plant and Soil 381, 215-224.

Wu, J., Wang, S., Cai, M., Wu, B., 2019. Review on on carbon use efficiency of plants and microbes and its influencing factors. Acta Ecologica Sinica 39, 7771-7779.

Wu, X., Xu, H., Tuo, D., Wang, C., Fu, B., Lv, Y., Liu, G., 2020. Land use change and stand age regulate soil respiration by influencing soil substrate supply and microbial community. Geoderma 359, 113991.

Zhou, H., Yu, W., Qiang, M., Lu, Z., 2009. A modified fumigation extraction method for the determination of soil microbial biomass carbon. Chinese Journal of Soil Science 40, 154-157.

Zhou, X., Chen, L., Xu, J., Brookes, P.C., 2020. Soil biochemical properties and bacteria community in a repeatedly fumigatedincubated soil. Biology and Fertility of Soils 56, 619-631.

Zhu, Z., Zeng, G., Ge, T., Hu, Y., Tong, C., Shibistova, O., He, X., Wang, J., Guggenberger, G., Wu, J., 2016. Fate of rice shoot and root residues, rhizodeposits, and microbe-assimilated carbon in paddy soil-Part 1: Decomposition and priming effect. Biogeosciences 13, 4481-4489 